\section{State of the art lecture: Endoscopic ultrasonography: Training and competence}

\author{
T. Rösch \\ Central Interdisciplinary Endoscopy Unit, Department of \\ Gastroenterology, Charité University Hospitals Berlin, Germany
}

Endoscopic ultrasonography (EUS) has become an important diagnostic and - recently - also therapeutic tool in gastrointestinal endoscopy, mostly complementary to other primary investigations. Its application in oncology as well as in a variety of benign conditions, the mixture of endoscopy and ultrasound as an imaging technique as well as the complexity of instrument handling to generate adequate visualization have all raised the necessity to define competence and hence design respective training programmes.

The following review shall give an overview on current programmes and the limited evidence of how to define competence and how to organize training. It has to be added that in most other areas of endoscopy with the recent possible exception of colonoscopy, data are scant as well.

Any training and its practical aspects have to be founded on the basis of sound theoretical and clinical knowledge not only of the technique under consideration including its potential complications, but also of the indications of EUS and the incorporation into clinical management of EUS and EUS-FNA as well as associated methods. No training programme whatsoever should only consist of teaching of practical application and technical aspects. Since this is a rather self-evident aspect, this is not dealt with further in the following, also with respect to the fact, that no standardization on the precise content of theoretical teaching exists, but at least clinical evidence can be collected from reviews, metaanalyses and textbooks.

Correspondence: Prof. Thomas Rösch, M.D. · Central Interdisciplinary Endoscopy Unit - Department of Gastroenterology, Hepatology and Metabolic Diseases · Charité University Hospitals Berlin, Campus Virchow Clinic · Augustenburger Platz 1·13353 Berlin·Germany·E-mail: Thomas.Roesch@charite.de

Bibliography: Endoscopy 2006; 38 (S1): S69-S72 @ Georg Thieme Verlag KG Stuttgart · New York · ISSN 0013-726X · DOI 10.1055/s-2006-946658
Formal EUS training programmes exist in only few countries. In Europe, France has by far the most advanced training curriculum, although this is still not officially accepted for credentialing. Nevertheless, a two years intensive programme has been described, involving theoretical introduction, 4 weeks of theoretical training and 20 one-day practical sessions per year [1]. Up to now, with the programme running since 1991, 20-25 doctors each year have undergone this curriculum, but data on outcome have not been published at least in the English speaking medical literature. In Germany, suggestions were made by a regional working group and included as prerequisites 1000 forward viewing and 200 side viewing endoscopies and 1000 abdominal ultrasound examinations, followed by specific requirements for EUS training, namely 200 examinations, of those 150 done by the trainees, backed up by courses and other teaching materials [2].

In the US, the ASGE has provided guidelines for credentialing and granting hospital privileges to perform routine gastrointestinal endoscopy [3] as well as advanced endoscopic procedures, which also includes EUS [4]. It was agreed that EUS should be dealt with separately from other endoscopic procedures. Attempts to create objective criteria by giving minimum numbers does not obviate the need for ultimately assessing competency the by training director or other independent tutor. The debate whether privileging in one or more of the various areas of EUS makes sense, may be considered separately, but adequate training has to be undergone in the areas for which privileging is requested. Nevertheless, a general consensus by EUS experts concluded that luminal (GI) EUS requires at least 3-6 months of intensive training to establish competency, whereas pancreaticobiliary EUS and FNA may need training for up to 1 year [5,6]. From the Asian-Pacific area, not many structured training programmes have come to the international attention.

\section{Evidence for EUS competence from the literature}

Logically, pre-EUS knowledge inlcudes sufficient expertise and safe handling of endoscope introduction (both forward and side-viewing) into the duodenum as well as knowledge in transabdominal ultrasound. The latter statement - beyond basic knowledge of principles of ultrasound and tissue visualization as well as artefacts - is not based on evidence. Non-systematic experience from countries in which ultrasound is integral part of gastroenterology training and from those in which ultrasound is firmly in the hands of radiologists shows that EUS examiners do not seem to perform differently at large. However, it is not analysed and reported in detail, which ultrasound training the trainees in non-ultrasound countries actually receive. US examiners have at least in the initial phase, used the advice and expertise of GI radiologists, which might have helped in image interpretation but surely not in instrument positioning to achieve these. As far as the author is aware, this is mostly not the case anymore in EUS training, and might only have helped the initial trainers to develop their knowledge.

Further to these basic facts, the next question is, how can competence be measured? By assessment of a trainee by an "experi- 
enced" examiner or by benchmarking of EUS accuracy in relation to acknowledged standards, e.g. surgical staging results? If the latter is the standard to be adhered to, we have to define accuracy limits which should be reached. These however, are hampered by a variety of facts and assumptions:

1. Published data on accuracy mostly come from expert centers where enthusiastic researchers have usually reached results well over $80 \%$ for staging accuracy. This however has been somewhat flawed by recent data on poor results in rectal and gastric cancer staging looking at average EUS application by variety of EUS examiners also including those with low numbers $[7,8]$. However, also data from speciality centers on rectal and pancreatic cancer staging $[9,10]$ have shed some doubts on high accuracy levels as reproducible gold standard.

2. Detailed definition of features defining EUS diagnoses are especially relevant for staging but have only rarely been systematically examined. Criteria were mostly defined in prospective studies measuring tumor staging accuracy, but at later stages never been systematically looked at : Does a slightly irregular outer tumor border already define stage T3, is this different in esophagus and stomach with their different $\mathrm{T}$ stage definitions, and what is irregular. There are studies on interobserver variability of EUS staging [11 - 13], but they have not systematically focused on image criteria aspects. Only one study on parameters of defining vascular involvement, although retrospective, has shown disappointing results [10]. The lack of precise data in this field is a major obstacle in defining training goals and quality assurance measures.

3. Especially for tumor staging, but also for other indications, histological control is difficult to obtain since patients are either not (submucosal tumors) or not primarily (neoadjuvant therapy) operated on in the vast majority of cases. So, simple benchmarking by obtaining accuracy data comparing EUS and histopathological results after surgery, are difficult or in some centers almost impossible.

4. Homogeneous accuracy data exist in other areas, especially in diagnosis of common bile duct stones [14 - 17]; here however, accuracy concerning negative findings can only be tested by careful follow-up [16,17], whereas positive EUS findings are usually easily controlled by ERCP with sphincterotomy.

5. Benchmarking of endoscopic results may raise a variety of other problems such as quality of data acquisition and external control mechanisms since these data inevitably will also be (ab)used for individual marketing of physicians or units.

For these and other reasons, its seems unrealistic, that each new EUS candidate delivers his/her accuracy rates based on data including follow-up of his/her patients for credentialing. Similarly, it will mean a great effort for established endosonographers to provide these data for recredentialing. Some surrogate parameter or as mentioned assessment by trainers might help but these have still to be defined.

At least, a few data exist on learning curves. Some studies have measured the accuracy in relation to EUS examination numbers in the GI tract. For visualization of normal structures, controlled by an experienced examiner, a prospective study has demonstrated that competent intubation of the esophagus, stomach, and duodenum was achieved in a median of 1-2 procedures (range 1 to 23), whereas visualization of the gastric or esopha- geal wall was achieved after a mean of $10-15$ EUS examinations (range 1 to 47). Adequate evaluation of the celiac axis region required some 10-15 EUS procedures (range 8-36) [18].

As early as 1996, Paul Fockens has reported on his learning curve of EUS staging of esophageal cancer between 1991 and 1993. After the first 36 cases, T staging accuracy was $58 \%$, rising to $83 \%$ in the subsequent 35 cases. The authors conclusion that 100 cases would be necessary, is based on these 71 cases but we do not know whether a further 30 cases would have further increased the T staging accuracy [19]. Another paper published in 1999 compared different years of EUS staging done by one examiner which were 64.5 for $1989,90 \%$ and $86 \%$ for 1997 and 1998 from a total of 112 traversable tumors staged between 1989 and 1998 . An accuracy of $68 \%$ after 49 cases rose to $90 \%$ after 74 , but it is not clear why these cut-offs were selected [20]. At least the study suggests, that once a stable accuracy level (here between 85 and $90 \%$ is achieved, it will probably not be increased further. Both studies let us conclude that for esophageal cancer staging, often thought to be one of the easiest EUS applications, staging accuracy well above $80 \%$ is only reached after some $70-75$ cases. Given the limited number of such cases outside speciality centers for esophageal cancer, competence will obviously take quite some time to be achieved. In a pretty small study on rectal cancer staging, 58 percent of the initial 12 studies were staged correctly compared with 87.5 percent accuracy in the remaining 24 examinations [21].

What does expert opinion suggest? A survey of the American Endosonography Club in 1995 suggested an average of 43, 44 and 37 EUS examinations for esophageal, gastric and rectal imaging [22]. The ASGE currently recommends a minimum of 75 supervised cases, at least two-thirds in the upper gastrointestinal tract, before competency for evaluating mucosal tumors can be assessed [4]; similar recommendations were given, based on expert opinion, also by the ESGE [23].

The situation in the pancreatobiliary area has always been regarded the most difficult one. A multicenter, 3-year prospective study reported that adequate imaging of the pancreatic and bile ducts required less cases to be done than of the pancreatic parenchyma (median 34 vs. 55, ranges $15-74$ vs. 13 to 135 cases) [18]. No studies exist on the learning curve in diagnosing pancreatobiliary disease. A survey from the American Endosonography Club suggests that interpretative competence of pancreatic images may require additional procedures, namely a total of 120 cases [22]. Other expert opinion suggests a higher threshold of 150 cases before assessing interpretative competence [24]. Currently, the ASGE Standards of Practice Committee recommend a minimum of 75 pancreatobiliary EUS examinations before competence can be assessed [4].

Finally, a prospective study assessing 4 physicians as well as one nurse evaluated visualization of GI and pancreatobiliary area and found competence as assessed by an experienced evaluator after approximately 25 esophageal, 35 gastric but 78 duodenal (including pancreatobiliary) examinations. The nurse, by the way, was tested only for esophageal/ mediastinal scanning and performed equally well [25]. 
There are only limited data on EUS-guided fine needle aspiration (FNA) - and those only for pancreatic puncture - which has evolved as a crucial addendum to the imaging capability of EUS, almost similarly to the relevance of biopsy for luminal endoscopy. In a very small collective of 20 patients who underwent EUSFNA by three examiners, the initial learning $(n=9)$ and the later period ( $\mathrm{n}=11$ ) was assessed and the accuracy increased from $33 \%$ to $91 \%$ [26], but such a small study is probably of limited value. Another study examined the first 57 pancreatic tumor FNA cases of one endosonographer, and again the accuracy rose from $40-50 \%(1-20)$ to the remaining ones (70-90\%) [27]. On the other side of the spectrum, for an obviously very talented endosonographer, the diagnostic accuracy after training on 45 cases in his $3^{\text {rd }}$ year fellowship did not increase overe his subsequent 300 cases, analysed by 100 cases each (92-95\%). Only the number of passes (from 4 to 3 ) and the complication rate (from $13-18 \%$ to $7 \%$ ) decreased [28].

For all other lesions lesions than in the pancreas (mediastinum, paragastric, e.g. lymph nodes, ascites, submucosal tumors), data are missing, however, it is assumed that pancreatic FNA may have the highest complexity and complication risk. It was therefore recommended that a trainee be competent in non-pancreatic EUS after at least 25 supervised FNA cases. The same publication, written before the abovementioned studies, suggested that for pancreatic FNA competence in diagnostic pancreaticobiliary EUS (at least 75 cases) has to be acquitted, and 25 supervised FNA procedures of pancreatic lesions have to be done [4].

From these few reports and studies we may conclude that case numbers given by experts or committees are usually lower than those shown in actual clinical testing. Nevertheless, practical aspects have to be taken into account, and it can be debated whether standards should be much higher than those set for other areas of GI endoscopy. An individualized approach in assessing competence may be superior, but has not been agreed upon as yet.

\section{Training tools}

The usual spectrum of self-teaching by textbooks and videos or CD-ROMs is recommended in almost all review articles and consensus statements as a basis for EUS training. The mention of course participation is another important step considered very helpful. A three-day educational course on EUS was assessed before and after in terms of knowledge of EUS indications in 4 anatomic sites and with 2 participants, and the knowledge increased by $4-20 \%$, mostly in esophagus and rectum [29]. There are courses of several levels, ranging from mere theory, to video demonstrations, live demos or participation (observation) in patient procedures to hands-on training in simulators and animals, and combination of some or all of the above aspects.

Training in simulators or models of various composition has been introduced quite a few years ago with great success in various areas of GI endoscopy such as hemostasis, polypectomy or other techniques including even therapeutic ERCP [30 - 32]. Several studies have shown its value in increasing skill $[33,34]$ which can also be objectively measured [35], and, most impor- tantly, that the learning phase in patients can be shortened. A recent randomized study using a sigmoidoscopy simulator showed a better performance in patients of the trainees undergoing simulation first when compared to a control group in a recent randomized trial [36].

For EUS, a variety of simulators has been described: The Simbionix Corporation (http://www.simbionix.com) which has several upper and lower GI as well as ERCP simulators has recently developed the first and only EUS module providing practice of EUS procedures. The adaption of VOXEL man for teaching EUS anatomy has been described by a German group [37]. Biomodels (EASIE, Erlangen trainer) have been modified to fit for EUS (no publications). Simpler models for training of EUS-FNA $[38,39]$ or cyst drainage [40] have been presented which are all useful to teach and train certain aspects of EUS imaging or FNA. Finally, training in live pigs is perhaps the most realistic, but also the most elaborate model $[41,42]$. Although not shown in randomized trials, the value of these models is likely to improve training and shorten the learning curve patients. Most probably, the value of the different models is rather complementary than competitive. The ideal training center for EUS will have most if not all of them available after appropriate testing.

\section{Suggestion for further actions}

Not surprisingly, teaching in EUS is mostly self-teaching up to recently. Of the attendees of the 12th International Symposium on EUS in October 2002 in New York, who were asked to complete a survey questionnaire on clinical practice of EUS, 191 participated (48.9\%), 110 from the United States, 81 from 30 different other countries. $53 \%$ of 102 endosonographers were in academic practice, a natural selection in such meetings, and $80 \%$ also performed ERCP. Almost half of the respondents had 1-5 years of experience. Only 19\% had more than 6 months of dedicated hands-on EUS training, and more than a third of the respondents learned EUS by observation or self teaching [43]. On the other hand, a survey among 76 EUS performers found that $93 \%$ and $89 \%$ felt that they had received adequate instruction for diagnostic EUS and EUS-FNA; $81 \%$ were trained during advanced (67\%) or normal GI fellowship (14\%) [44].

What we may need to better approach the problem of EUS competency and training has to be developed in consensus and may include the following

- Definition of EUS features of various disorders, ranging from precise parameters for tumor staging to the diagnosis of benign disorders for teaching and setting standards of training

- Discussion about quality programmes in EUS in relation to possible benchmark data concerning indications, accuracy and complications; they should be easy, practicable and reproducible

- Definition of a training curriculum including theory, hands-on training (such curricula have been defined for model training of GI endoscopy in Germany (www.dgvs.de) and the US (45) and finally in patients

- Tackling the difficult problem of how to assess competency, initially (credentialing) and possibly also later (recredentialing) 
Only if we can better standardize the performance and features of EUS as well as the definition of competency and training we will help to improve EUS quality and finally its incorporation into better patient care.

\section{References}

${ }^{1}$ Rosch T. EUS training in Europe. Endoscopy 1998 Aug; 30 Suppl 1: A18 ${ }^{2}$ Krakamp B, Janssen J, Menzel J et al. Requirements and recommendations for performing endosonographies - comments by the working groupon endoscopic ultrasound in North Rine Westphalia. Z Gastroenterol 2004; 42: 157-166

${ }^{3}$ ASG E. Guidelines for credentialing and granting privileges for gastrointestinal endoscopy. Gastrointest Endosc 1998; 48: 679-682

${ }^{4}$ ASG E. Guidelines for credentialing and granting privileges for endoscopic ultrasound. Gastrointest Endosc 2001; 54: 811 -814

${ }^{5}$ ASG E. Role of endoscopic ultrasonography. Gastrointest Endosc 2000; 52: $852-859$

${ }^{6}$ Lightdale CJ. EUS training in the USA. Endoscopy 1998 Aug; 30 Suppl 1: A19-21

${ }^{7}$ Marusch F, Koch A, Schmidt U, Zippel R, Kuhn R, Wolff S, Pross M, Wierth A, Gastinger I, Lippert $\mathrm{H}$. Routine use of transrectal ultrasound in rectal carcinoma: results of a prospective multicenter study. Endoscopy. 2002 May; 34 (5): 385 - 390

${ }^{8}$ Meyer L, Meyer F, Marusch F et al. Endosonographie im präoperativen Staging des Magenkarzinoms - Anspruch und Realität. Z Gastroenterol 2005; 43: 934

${ }^{9}$ Kauer WK, Prantl L, Dittler HJ, Siewert JR. The value of endosonographic rectal carcinoma staging in routine diagnostics: a 10-year analysis. Surg Endosc. 2004 Jul; 18 (7): 1075 - 8. Epub 2004 May 27

${ }^{10}$ Rösch T, Dittler HJ, Strobel K, Meining A, Schusdziarra V, Lorenz R, Allescher HD, Kassem AM, Gerhardt P, Siewert JR, Hofler H, Classen M. Endoscopic ultrasound criteria for vascular invasion in the staging of cancer of the head of the pancreas: a blind reevaluation of videotapes. Gastrointest Endosc 2000 Oct; 52(4): 469-477

${ }^{11}$ Meining A, Rosch T, Wolf A, Lorenz R, Allescher HD, Kauer W, Dittler HJ. High interobserver variability in endosonographic staging of upper gastrointestinal cancers. Z Gastroenterol 2003 May; 41 (5): 391 - 394

12 Burtin P, Rabot AF, Heresbach D, Carpentier S, Rousselet MC, Le Berre N, Boyer J. Interobserver agreement in the staging of rectal cancer using endoscopic ultrasonography. Endoscopy 1997 Sep; 29 (7): 620-625

${ }^{13}$ Gress F, Ciaccia D, Schmitt C et al. Interobserver agreement among endosonographers for staging of pancreatic cancer by endoscopic ultrasound. Gastrointest Endosc 1997; 45: $138-142$

${ }^{14}$ Kondo S, Isayama H, Akahane M, Toda N, Sasahira N, Nakai Y, Yamamoto N, Hirano K, Komatsu Y, Tada M, Yoshida H, Kawabe T, Ohtomo K, Omata M. Detection of common bile duct stones: comparison between endoscopic ultrasonography, magnetic resonance cholangiography, and helical-computed-tomographic cholangiography. Eur J Radiol 2005 May; 54 (2): 271 - 275

15 Palazzo L, O'toole D. EUS in common bile duct stones. Gastrointest Endosc. 2002 Oct; 56 (4 Suppl): S49-57

${ }^{16}$ Napoleon B, Dumortier J, Keriven-souquet O, Pujol B, Ponchon T, Souquet JC. Do normal findings at biliary endoscopic ultrasonography obviate the need for endoscopic retrograde cholangiography in patients with suspicion of common bile duct stone? A prospective follow-up study of 238 patients. Endoscopy 2003 May; 35 (5): 411 - 415

17 Berdah SV, Orsoni P, Bege T, Barthet M, Grimaud JC, Picaud R. Followup of selective endoscopic ultrasonography and/or endoscopic retrograde cholangiography prior to laparoscopic cholecystectomy: a prospective study of 300 patients. Endoscopy 2001 Mar; 33 (3): 216 - 220

${ }^{18}$ Hoffman B, Wallace MB, Eloubeidi MA et al. How many supervised procedures does it take to become competent in EUS? Results of a multicenter three year study. Gastrointest Endosc 2000; 51: AB139

${ }^{19}$ Fockens P, Van den Brande JHM, van Dullemen HM et al. Endosonographic T-staging of esophageal carcinoma: a learning curve. Gastrointest Endosc 1996; 44: 58-62

${ }^{20}$ Schlick T, Heintz A, Junginger T. The examiner's learning effect and its influence on the quality of endoscopic ultrasonography in carcinoma of the esophagus and gastric cardia. Surg Endosc 1999; 13: $894-898$
${ }^{21}$ Carmody BJ, Otchy DP. Learning curve of transrectal ultrasound. Dis Colon Rectum 2000 Feb; 43 (2): 193 - 197

${ }^{22}$ Hoffman BJ, Hawes RH. Endoscopic ultrasound and clinical competence. Gastrointest Endosc Clin North Am 1995; 5: 879-884

${ }^{23}$ Caletti G, Deviere J, Fockens P, Lees WR, Mortensen B, Odegaard S, Rosch T, Souquet JS, Vilmann P. Guidelines of the European Society of Gastrointestinal Endoscopy (ESGE) Part II: Retroperitoneum and large bowel, training. The European Endosonography Club Working Party. Endoscopy 1996 Sep; 28 (7): 626-628

${ }^{24}$ Boyce HW. Training in endoscopic ultrasonography. Gastrointest Endosc 1996; 43: S12-15

${ }^{25}$ Meenan J, Andreson S, Tsang S et al. Training in radial EUS: What is the best approach and is there a role for the nurse endoscopist? Endoscopy $2003 ; 35: 1020-1023$

${ }^{26}$ Harewood GC, Wiersema LM, Halling AC et al. Influence of EUS training and pathology interpretation on accuracy of EUS-guided fine needle aspiration of pancreatic masses. Gastrointest Endosc 2002; 55: 669-673

${ }^{27}$ Mertz H, Gautam S. The learning curve for EUS-guided FNA of pancreatic cancer. Gastrointest Endosc 2004; 59: 33 - 37

${ }^{28}$ Eloubeidi MA, Tamhane A. EUS-guided FNA of solid pancreatic masses: A learning curve with 300 consecutive procedures. Gastrointest Endosc 2005; 61: 700-708

${ }^{29}$ Harewood GC, Yusuf TE, Clain JE et al. Assessment of the impact of an educational course oin knowledge of appropriate EUS indications. Gastrointest Endosc 2005; 61: 554-559

${ }^{30}$ Gerson LB, Van Dam J. Technology review: the use of simulators for training in GI endoscopy. Gastrointest Endosc 2004 Dec; 60 (6): $992-1001$

${ }^{31}$ Hochberger J, Maiss J, Hahn EG. The use of simulators for training in GI endoscopy. Endoscopy 2002 Sep; 34 (9): 727 - 729

32 Grantcharov TP, Carstensen L, Schulze S. Objective assessment of gastrointestinal endoscopy skills using a virtual reality simulator. JSLS 2005 Apr-Jun; 9 (2): 130 - 133

${ }^{33}$ Hochberger J, Matthes K, Maiss J, Koebnick C, Hahn EG, Cohen J. Training with the compactEASIE biologic endoscopy simulator significantly improves hemostatic technical skill of gastroenterology fellows: a randomized controlled comparison with clinical endoscopy training alone. Gastrointest Endosc 2005 Feb; 61 (2): 204-215

${ }^{34}$ Sedlack RE, Kolars JC, Alexander JA. Computer simulation training enhances patient discomfort during endoscopy. Clin Gastroenterol Hepatol 2004; 2 : $348-352$

${ }^{35}$ Neumann M, Friedl S, Meining A, Egger K, Heldwein W, Rey JF, Hochberger J, Classen M, Hohenberger W, Rosch T. A score card for upper GI endoscopy: Evaluation of interobserver variability in examiners with various levels of experience. Z Gastroenterol 2002 Oct; 40 (10): 857 - 862

${ }^{36}$ Gerson LB, Van Dam J. A prospective randomized trial comparing a virtual reality simulator to bedside teaching for training in sigmoidoscopy. Endoscopy 2003 Jul; 35 (7): 569-575

37 Burmester E, Leineweber T, Hacker S, Tiede U, Hutteroth TH. EUS Meets Voxel-Man: three-dimensional anatomic animation of lineararray endoscopic ultrasound images. Endoscopy 2004 Aug; 36 (8): $726-730$

${ }^{38}$ Sorbi D, Vazquez-Sequeiros E, Wiersema MJ. A simple phantom for learning EUS-guided FNA. 2003 Apr; 57 (4): 580-583

${ }^{39}$ Bussen D, Sailer M, Fuchs KH et al. A teaching model for endorectal ultrasound-guided biopsy and drainage of rectal tumors. Endoscopy 2004; 36: $217-219$

${ }^{40}$ Schofl R, Buchmeier B, Hauder G. Adaptation of the Erlangen Active Simulator for Interventional Endoscopy (EASIE) model for transmural pancreatic pseudocyst drainage. Endoscopy 2006 Jan; 38 (1): 100

41 Bhutani MS, Hoffman BJ, Hawes RH. A swine model for teaching endoscopic ultrasound (EUS) imaging and intervention under EUS guidance. Endoscopy 1998 Sep; 30 (7): 605-609

42 Bhutani MS, Aveyard M, Stills Jr HF. Improved model for teaching interventional EUS. Gastrointest Endosc 2000; 52: 400-403

${ }^{43}$ Das A, Mourad W, Lightdale C et al. An international survey of the clinical practice of EUS. Gastrointest Endosc 2004; 60: 765-770

${ }^{44}$ Wasan SM, Kapadia AS, Adler DG. EUS training and practice patterns among gastroenterologists completing training since 1993. Gastrointest Endosc 2005; 62: 914-920

${ }^{45}$ Sedlack RE, Kolars JC. Colonscopy curriculum development and performance-based criteria on a computer-based endoscopy simulator. Acad Med 2002; 77: 750-751 